\title{
Revision of the Criticism Avoidance dimension of the Dimensional Clinical Personality Inventory
}

\author{
Revisão da dimensão Evitação a Críticas \\ do Inventário Dimensional Clínico \\ da Personalidade
}

\author{
Lucas de Francisco CARVALHO \\ Catarina Possenti SETTE ${ }^{1}$
}

\begin{abstract}
The aim of this study was to revise the Criticism Avoidance dimension of the Dimensional Clinical Personality Inventory and to investigate its psychometric properties. The participants included 213 subjects aged 18 to 69 years (Mean $=25.56$; Standard Deviation $=8.70)$, mostly females $(N=159 ; 74.3 \%)$. All participants answered the Dimensional Clinical Personality Inventory and the Brazilian versions of the Revised NEO Personality Inventory and the Personality Inventory for DSM-5. A total of 470 new items were developed and selected using content analysis, and 39 items composed the final version. Based on the parallel analysis and factor analysis, three interpretable factors were found. The internal consistency coefficients showed adequate levels of reliability ranging between 0.80 and 0.91 for the factors. Additionally, expected correlations were found between the Dimensional Clinical Personality Inventory and the other tests. The present study demonstrated the adequacy of the dimension revised to assess pathological characteristics of the avoidant personality functioning.
\end{abstract}

Keywords: Personality disorders; Personality traits; Psychometrics.

\section{Resumo}

O objetivo do presente estudo foi revisar a dimensão Evitação a Críticas do Inventário Dimensional Clínico da Personalidade, investigando, também, suas propriedades psicométricas. Participaram 213 sujeitos, com idade variando entre 18 e 69 anos (Média = 25,56; Desvio-Padrão = 8,70), sendo a maior parte do sexo feminino ( $N=159 ; 74,3 \%)$. Todos os participantes responderam o Inventário Dimensional Clínico da Personalidade e as versões brasileiras do Inventário NEO de Personalidade-Revisado e do Personality Inventory for DSM-5. Foram desenvolvidos 470 novos itens

\footnotetext{
1 Universidade São Francisco, Programa de Pós-Graduação Stricto Sensu em Psicologia. R. Alexandre Rodrigues Barbosa, 45, Centro, 13251-900, Itatiba, SP, Brasil. Correspondência para/Correspondence to: L.F. CARVALHO. E-mail: <lucas@labape.com.br>

Support: Fundação de Amparo à Pesquisa do Estado de São Paulo.

Acknowledgements: Ananias Queiroga Filho, Hellida Lustosa Luz, Lucas Dannilo Aragão Guimarães and Maria do Socorro Albergaria de Castro.
} 
e selecionados, por meio de análise de conteúdo, 39 para compor a versão final de aplicação. Com base na análise paralela e análise fatorial, três fatores interpretáveis foram encontrados. Os coeficientes de consistência interna mostraram-se adequados, variando entre 0,80 e 0,91 para os fatores. Foram encontradas, ainda, correlações esperadas entre o Inventário Dimensional Clínico da Personalidade e os outros testes utilizados. Ressalta-se a adequabilidade da dimensão revisada na avaliação de traços patológicos do funcionamento evitativo da personalidade.

Palavras-chave: Transtornos da personalidade; Traços de personalidade; Psicometria.

The use of psychological tests with consistent psychometric properties with the Brazilian population (Hutz, 2009; Hutz \& Bandeira, 2003) has received growing attention in recent decades. Accordingly, there is a need to develop national psychological assessment instruments, especially those related to personality disorders (Carvalho, Bartholomeu, \& Silva, 2010). The literature suggests that personality disorders are among the most common disorders treated in psychology and psychiatric clinical practice (American Psychiatry Association, 2013; Zuccolo, Corhs, \& Savoia, 2013).

In Brazil, there are few psychological instruments to evaluate pathological personality traits from a broad perspective (Carvalho et al., 2010). Based on this scenario, Carvalho and Primi (2015) have developed the Dimensional Clinical Personality Inventory (IDCP, Inventário Dimensional Clínico da Personalidade), a self-report instrument to assess pathological personality traits based on Millon's theory (Millon \& Davis, 1996; Millon \& Grossman, 2007a, 2007b; Millon, Grossman, \& Tringone, 2010; T. Millon, Millon, Meagher, Grossman, \& Ramanath, 2004) and on the diagnostic criteria of axis II of the 4th edition, text revision, of the Diagnostic and Statistical Manual of Mental Disorders (DSM IV-TR; American Psychiatry Association, 2003). The instrument developed consists of 163 items categorized into 12 dimensions: Dependency, Aggressiveness, Mood Instability, Eccentricity, Attention Seeking, Distrust, Grandiosity, Isolation, Criticism Avoidance, Selfsacrifice, Conscientiousness, and Impulsiveness. Carvalho and Primi (2015), Carvalho, Primi, and Stone (2014) and Carvalho (2011) carried out analyses demonstrating the adequate reliability of the IDCP dimensions and favorable validity evidence based on the internal structure and external instrument dimensions need improvement to enhance the representativeness of the constructs evaluated and assure that the psychometric properties are continuously verified.

Therefore, the main focus of the present study was revising the Criticism Avoidance dimension of the IDCP. This dimension mainly assesses common characteristics of avoidant personality disorder, and it is characterized by individual beliefs of failure and that consequently others will humiliate or criticize them (Carvalho, 2011). As a result, these people may experience persecutory delusions, have exaggerated anxiety in social situations, and interpret others' actions as hostile.

Additionally, it is noteworthy that the avoidant personality disorder was kept by the proponents in the hybrid model for the fifth edition of the Diagnostic and Statistical Manual of Mental Disorders (DSM-5) (American Psychiatry Association, 2013), which comprises the evaluation method of the categorical and the dimensional approaches in a non-integrative way (Skodol et al., 2011). However, this proposal has not yet been accepted to replace the categorical model in the diagnostic manuals, and it is included in section 3 of the DSM- 5 as one of the models that needs further research (American Psychiatry Association, 2013).

The DSM-5 (American Psychiatry Association, 2013), in the chapter devoted to personality disorders, defines avoidant personality disorder as a pervasive pattern of social inhibition, feelings of inadequacy, and hypersensitivity to negative evaluation. This pattern includes low selfesteem, characteristics associated with excessive feelings of shame or inadequacy, and avoidance of situations and activities involving interpersonal contact because of fear of criticism and/or 
disapproval. People who exhibit avoidant behavior have a tendency towards sadness, irritability, and mood oscillations.

Moreover, individuals with this disorder tend to become more isolated due to hypersensitivity to rejection, despite their desire for affection and acceptance, have a tendency to develop intense attachments to the few people with whom they can relate. Avoidant people also tend to express deep distrust, which is related to feelings of inadequacy and shame. Thus, the behavior of individuals diagnosed with avoidant personality disorder is characterized by social withdrawal, but at the same time they want to have close social relationships, that is, they live in a state of constant ambivalence causing psychological distress. Therefore, they tend to avoid social contact for fear of feeling of being humiliated or rejected, exhibiting shyness and avoidance as defense mechanisms against embarrassing situations, in which the individual is dominated by intense fear of rejection or failure (American Psychiatry Association, 2013; Yazigi et al., 2013).

Section 3 of the DSM-5, which describes the hybrid model, also includes some characteristics presented under criterion B, which are typically related to the avoidant personality disorder: Anxiety (intense nervousness and tension as a reaction to social situations, concern with the negative effects of unpleasant past experiences, and feelings of apprehension about the future); Avoidance (shyness in social situations and lack of initiative of interpersonal contact); Anhedonia (inability to experience pleasure or interest in things and lack of involvement or energy in life); and Avoidance of Intimacy (avoidance of intimate or romantic relations) (American Psychiatry Association, 2013).

Abela (2013) carried out an empirical study in Brazil to investigate the personality profile of patients diagnosed with personality disorders using the IDCP. The author compared the profile of a group of people with avoidant personality disorder without comorbid disorders $(\mathrm{N}=10)$ with the profile of a group of people with avoidant personality disorder with comorbid disorders $(N=42)$ and with the rest of the sample, people with a Personality Disorder but without avoidant personality disorder $(\mathrm{N}=35)$. There was a significant difference between the profiles $(F=3.93 ; p=0.001)$, and the group with avoidant disorder and without comorbid disorders had high scores on the Criticism Avoidance dimension, moderate scores on the Dependency factor dimension, and low scores on Attention Seeking dimension. On the other hand, the group with avoidant disorder and comorbid disorders had higher scores on the dimensions Criticism Avoidance, Dependency, Eccentricity, Mood Instability, Isolation, Self-sacrifice, and Distrust and low scores on the Attention Seeking dimension. It is important to mention that in the last group exhibited a typical functioning of other personality disorders (comorbidity). Nevertheless, the data found confirmed the hypothesis of Carvalho (2011) and Carvalho and Primi (2015) that the Criticism Avoidance dimension has a direct relationship with the avoidant personality disorder.

Therefore, some studies have demonstrated that the IDCP has adequate psychometric properties (Carvalho, 2011; Carvalho \& Primi, 2015; Carvalho et al., 2014) and others have shown its clinical utility for profile assessment, specifically in relation to the Criticism Avoidance dimension and avoidant functioning, which are the focus of this research. Thus, studies have been conducted aimed at improving the IDCP in terms of assuring the refinement of its dimensions and that the psychometric properties are continuously verified. Some examples are the study carried out by Carvalho, Sette, Capitão, and Primi (2014a), concerning the revision of Attention Seeking dimension, and the study by Carvalho, Souza, and Primi (2014b), which focused on revising the Conscientiousness dimension.

Based on the aforementioned discussion and the need for improvement in the IDCP dimensions, the present study aimed to revise the Criticism Avoidance dimension and to verify the psychometric properties of the new version of this dimension. It is important to mention that it was expected to find factors composing the new dimension to enable 
evaluation of personality profiles within the dimension, i.e., to find subscores with moderate correlations among themselves rather than a single total score demonstrating the different characteristics to be evaluated by the dimension.

\section{Method}

In order to achieve the objectives established, the method used in this research was divided into two parts, stages I and II. The first part (Stage I) referred to the procedures for the revision of the Criticism Avoidance dimension; the second part (Stage II) referred to the information about the verification of the psychometric proprieties of the dimension.

\section{Procedures for revision of the Criticism Avoidance dimension (Stage I)}

For the revision of the dimension, i.e., the development of a new set of items to be included in the instrument, a procedure comprising six different stages, which replicates other procedures that were previously adopted to revise the IDCP dimensions, was adopted (Carvalho et al., 2014a, 2014b). It should be highlighted that all steps were carried out by the authors of this study. One of the judges was a graduate student, who was enrolled in a Master's program in psychological evaluation and who had published articles in the same area and is a member of a group for the study of personality disorders. The other judge holds a PhD in Psychology, specifically in the assessment of pathological personality characteristics and personality disorders, including the development of instruments in this area. The first stage was characterized by the literature review on the characteristics related to the Criticism Avoidance dimension and the Avoidant Personality disorder. It was based on four main sources: the fifth edition of the DSM (DSM-5; American Psychiatry Association, 2013); the dimensions comprising the

222 Personality Inventory for DSM-5 (PID-5; Krueger,
Derringer, Markon, Watson, \& Skodol, 2011), the dimensions assessed by the Shedler-Westen Assessment Procedure (SWAP); (Shedler \& Westen, 2004); and the dimensions proposed by Clark (1990), which give basis for the Schedule for Nonadaptive Personality. These sources were selected because of their prominence in the area and to the fact they especially address the pathological characteristics of personality, enhancing representativeness of the underlying construct of the Criticism Avoidance dimension.

In the second phase, the constructs and dimensions related to the IDCP dimension and the common characteristics of avoidant personality disorder were selected and organized into a data input spreadsheet, according to the sources cited. The definitions and sentences of the selected material were entered into the spreadsheet in the original language (English) and translated independently by the authors of this study, who produced together an agreed version agreed version of the final translation.

In the third phase, the operationalization of the selected constructs was performed, i.e., the development of new items for the Criticism Avoidance dimension based on the information organized into the spreadsheet, as previously described. In the following stage, stage 4, the researchers selected, separately, the items that were deemed most appropriate from a conceptual standpoint. These items were then compared, and the researchers reached a consensus on the selected items.

In stage five, the items were grouped into categories according to their content and originality, i.e., items that were present in the original version of the dimension were also allocated to the new categories created. Thus, the new and the original items could be compared in terms of the specific contents assessed; the new items with redundant content were excluded. Finally, in the last stage, the final selection of the new items to compose the final revised version of the Criticism Avoidance dimension was made. 


\section{Verification of the psychometric properties of the Criticism Avoidance dimension (Stage II)}

\section{Participants}

Participants included 213 subjects, aged between 18 and 69 years $(M=25.56, S D=8.70)$, 159 females (74.3\%). Most participants had incomplete higher education (83.6\%); 8.9\% had complete higher education. They were selected from two private universities in the state of São Paulo, Brazil using convenience sampling. As for their history of psychiatric treatment, $7.5 \%$ of subjects reported having already undergone psychiatric treatment, $4.7 \%$ reported being under treatment, and $5.1 \%$ had already made use of psychotropic medication. As for psychological counseling, $23.4 \%$ of participants reported having undergone psychotherapy, and only $7.5 \%$ were undergoing it.

\section{Instruments}

Three instruments administered in this research, the IDCP (Carvalho \& Primi, 2015); the Brazilian version of the Revised NEO Personality Inventory (NEO-PI-R) (Costa Junior \& McCrae, 2009); and the Brazilian version of the Personality Inventory for DSM-5 (PID-5) (Krueger et al., 2011). As previously mentioned, the IDCP is a self-report instrument developed to assess pathological personality traits based on the theory of Millon et al. (2004) and the diagnostic criteria of axis II of the DSM-IV-TR (American Psychiatry Association, 2003). The IDCP consists of 163 items categorized into 12 dimensions (Dependency, Aggressiveness, Mood Instability, Eccentricity, Attention Seeking, Distrust, Grandiosity, Isolation, Criticism Avoidance, Self-sacrifice, Conscientiousness, and Impulsiveness to be scored on a 4-point Likert-like scale, in which 1 is "it has nothing to do with me" and 4, "it has everything to do with me", with an average administration time of 25 minutes. The psychometric properties of the IDCP were verified by Carvalho and Primi (2015), Carvalho et al. (2014b), and Carvalho (2011), who found that, in general, they confirm the adequacy of this instrument. It is noteworthy that the new set of items that compose the Criticism Avoidance dimension has the same format as the other IDCP dimensions.

Another instrument used was the Brazilian version of the NEO-PI-R (Costa Junior \& McCrae, 2009), which is a self-report inventory composed of 240 items that are rated on a 5-point Likert-like scale ranging from "strongly disagree" (1) to "strongly agree" (5). It is used to assess personality traits in adults using five dimensions, Neuroticism, Extraversion, Openness to Experience, Agreeableness, and Conscientiousness. The average administration time is 25 minutes. The manual of the Brazilian version of this instrument contains a list of several studies showing validity evidence and good reliability (Costa Junior \& McCrae, 2009). In the present study, the dimensions Neuroticism $(\alpha=0.80)$ and Extraversion ( $\alpha=0.53$ ) dimensions were considered. According to Nunnally (1978), the Cronbach alpha should be greater than 0.7. Therefore, alpha values less than 0.70 should be carefully considered during discussion and analysis of the scores obtained.

The translated and adapted version of the PID-5 (Krueger et al., 2011) was also administered. This is a self-report inventory to assess pathological personality traits and consists of 220 items and 25 facet-level traits (grouped in five dimensions) to be rated on a 4-point Likert-like scale ranging from zero ("very false" or "often false") to 3, ("very true" or "often true"). The PID-5 was developed to measure criterion $B$ of this hybrid model in section 3 of the DSM-5 (American Psychiatry Association, 2013). There are no national studies addressing the verification of the psychometric properties of the Brazilian version of this instrument, but Krueger et al. (2011) reported data indicating the adequacy of the original version of this instrument. The following facets were considered in the present study: Anxiety $(\alpha=0.71)$, Depressiveness $(\alpha=0.72)$, Avoidance of Intimacy $(\alpha=0.50)$, and Avoidance $(\alpha=0.63)$. 


\section{Procedures}

Data were collected after submission and approval by the Research Ethics Committee (Process $n^{\circ}$ 21992113.1.0000.5514). The instruments were administered collectively in the classrooms of two private universities (state of São Paulo) in a single session per classroom with an average duration of 40 minutes. However, due to demand and access, some were administered in each campus individually. After the research objectives were explained, the participants signed the Free and Informed Consent and then responded the instruments.

After being collected, data were tabulated and were subjected to statistical analysis. Considering the objectives of this study, firstly, the number of factors to be kept in the exploratory factor analysis were determined based on the parallel analysis (Hayton, Allen, \& Scarpello, 2004; Watkins, 2006). Placement analysis was carried out using $R$ Statistical software (version 2.15.3), which allows the use of parallel analysis for polychoric variables.

A database was then created using the MPlus software (version 6.12) in order to carry out the exploratory factor analysis with polychoric variables, and the indices obtained indicated the adequacy of the structure found based on the sample evaluated in the present studied. It should be highlighted that the adequacy of the fit indices also suggests adequacy of the sample for carrying out the analyses. Finally, correlation analyses were conducted to examine the relationship between the factors found for the Revised Criticism Avoidance, the two dimensions of the NEO-PI-R, and the four facets of the PID-5. The difference between two dependent correlations was also calculated to indicate whether the difference between two correlation coefficients is significant or not.

\section{Results}

With regard to the first step, as previously described, the DSM-5, the PID-5, and the SWAP and Clark models were used. As for the DSM-5, dimension is avoidant personality disorder, and the dimensions considered in this study were identity, self-direction, intimacy, withdrawal, avoidance of intimacy, anhedonia (inability to experience pleasure), and anxiety. Among the 25 PID-5 facets (instrument to assess personality traits according to the criterion B of the hybrid model for DSM-5), the following were used: anhedonia, anxiety, withdrawal, and avoidance of intimacy.

As for the SWAP, Shedler and Westen (2004) conducted a study introducing 12 factors related to pathological personality traits, and the dysphoria factor refers to traits related to the Criticism Avoidance dimension of the IDCP since it refers to sentences related to feelings of inadequacy, inferiority, apathy, discouragement, depression, tendency to see life as empty and meaningless, difficulty finding pleasure or satisfaction in life activities, and tendency to avoid social situations for fear of embarrassment or humiliation. On the other hand, the model proposed by Clark (1990) contains factors related to the Criticism Avoidance dimension of the IDCP and the avoidant personality disorder: self-effacement, negative affect, social withdrawal, hypersensitivity, and pessimism. Based on the selected constructs and dimensions, a total of 470 items were developed, distributed according to the constructs, as demonstrated in Table 1.

It is worth mentioning that of the total set of items; the most suitable were pre-selected consensually (based on content, considering the revised dimension) resulting in a set of 67 items. In order to reduce the number of items, a second selection was made and 39 items remained; the redundant items were excluded. The number of items developed ranged from 9 to 91 per construct selected; the number of pre-selected items ranged from 0 to 15; and the number of selected items ranged from 0 to 9 , depending on the construct.

There were no any items selected for the dimensions dysphoria, negative affect, hypersensitivity, and pessimism in the final stage since the items were redundant, and the objective was to introduce items that would enhance the representativeness of the construct in this dimension, with different content from that in the original version. Some constructs, such as 


\begin{tabular}{|c|c|c|c|c|}
\hline Source & Construct & Developed & Pre-selected & Selected \\
\hline \multirow{7}{*}{ 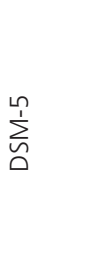 } & Identity & 10 & 2 & 8 \\
\hline & Self-direction & 9 & 2 & 9 \\
\hline & Intimacy & 10 & 1 & 6 \\
\hline & Withdrawal & 10 & 2 & 5 \\
\hline & Intimacy Avoidance & 9 & 2 & 2 \\
\hline & Anhedonia & 9 & 2 & 2 \\
\hline & Anxiety & 10 & 1 & 0 \\
\hline \multirow{4}{*}{$\begin{array}{l}\text { ำ } \\
\text { ํㅡㅁ }\end{array}$} & Anhedonia & 72 & 15 & 2 \\
\hline & Anxiety & 63 & 14 & 1 \\
\hline & Withdrawal & 91 & 14 & 1 \\
\hline & Intimacy Avoidance & 52 & 10 & 1 \\
\hline$\sum_{n}^{\frac{1}{3}}$ & Dysphoria & 76 & 0 & 0 \\
\hline \multirow{5}{*}{ 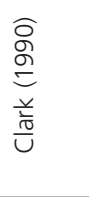 } & Self-annulation & 10 & 1 & 1 \\
\hline & Negative affection & 10 & 0 & 0 \\
\hline & Social isolation & 9 & 1 & 1 \\
\hline & Hipersensibility & 10 & 0 & 0 \\
\hline & Pessimism & 10 & 0 & 0 \\
\hline Total & & 470 & 67 & 39 \\
\hline
\end{tabular}

Note: SWAP: Shedler-Westen Assessment Procedure; PID-5: Personality Inventory for DSM-5; DSM-5: Diagnostic and Statistical Manual of Mental Disorders, 5th Edition.

withdrawal and anxiety, are repeated in Table 1 because the PID- 5 is based on the DSM-5, also used in this study; however, the construct definitions were based on the DSM-5 and PID-5 items were used, which are as similar but not identical.

Next, the 39 items were grouped into categories arbitrarily created by the researchers to identify the representativeness of the items developed and to group the items of the original version the revised scale. It is should be noted that the number of items by category (between four and ten) was aimed to represent the previously selected content. It was observed that most $(\mathrm{N}=4)$ of the original items encompassed the Social Avoidance construct, and that the development of new items contributed to the inclusion in the Criticism Avoidance dimension in the characteristics normally related to avoidant personality disorder (in anxiety, avoidance of intimacy, feelings of inadequacy, and isolation). Thirty nine new items were selected to compose the new dimension, as the final set of items.

After the final selection of new (39) and original (7) items, the psychometric properties were investigated. The maximum number of factors for the revised dimension was determined based on the parallel analysis for polychoric variables. Three factors with significant eigenvalue and which were not formed randomly were found. According to this information, an Exploratory Structural Equation Modeling (ESEM) analysis was carried out forcing one to three factors using Geomin oblique rotation, and the Robust Maximum Likelihood (MLR) extraction method, which is considered as a robust method suitable for polychoric variables.

Based on these data, the adjustment indices generated for the two models were analyzed, and the three-factor model was the most appropriate, which can be verified by indices $\chi^{2} / \mathrm{df}=1.97$ (good); RMSEA $=0.070$ (adequate); $C F I=0.754$ (unsatisfactory); and SMR $=0.060$ (good). The factor loadings, the number of items kept in each factor, and the internal consistency index (Cronbach's alpha) are shown in Table 2 . The items remaining in each factor are bold-faced in gray shaded table cells.

As can be seen from Table 2, the final version of the scale was composed of 18 items distributed 
Exploratory factory analysis and internal consistency indices

\begin{tabular}{cccc}
\hline Items & Anxious Preoccupation & Generalized Avoidance & Avoidance of Intimal Relationships \\
\hline 34 & 0.260 & $\mathbf{0 . 5 6 6}$ & 0.087 \\
83 & 0.421 & $\mathbf{0 . 5 5 3}$ & 0.044 \\
466 & 0.374 & $\mathbf{0 . 6 8 4}$ & 0.211 \\
468 & $\mathbf{0 . 6 6 3}$ & 0.273 & 0.039 \\
469 & $\mathbf{0 . 7 3 2}$ & 0.324 & 0.133 \\
470 & $\mathbf{0 . 5 7 8}$ & 0.184 & 0.003 \\
471 & $\mathbf{0 . 7 0 6}$ & 0.352 & 0.126 \\
477 & 0.207 & $\mathbf{0 . 5 5 7}$ & 0.190 \\
481 & 0.269 & $\mathbf{0 . 5 2 4}$ & 0.146 \\
483 & 0.371 & $\mathbf{0 . 6 7 2}$ & 0.144 \\
486 & 0.352 & 0.332 & $\mathbf{0 . 8 1 7}$ \\
487 & 0.308 & 0.340 & $\mathbf{0 . 8 2 6}$ \\
488 & 0.115 & 0.346 & $\mathbf{0 . 8 7 7}$ \\
489 & 0.290 & 0.416 & $\mathbf{0 . 7 8 9}$ \\
494 & 0.327 & $\mathbf{0 . 5 4 2}$ & 0.137 \\
496 & 0.541 & $\mathbf{0 . 6 6 4}$ & 0.197 \\
499 & 0.443 & $\mathbf{0 . 7 0 9}$ & 0.180 \\
503 & 0.231 & $\mathbf{0 . 6 0 5}$ & 0.395 \\
\hline of items & 4 & 10 & 4 \\
\hline
\end{tabular}

Note: The table present only the items that were kept, facilitating the data visualization.

into three factors, ranging from four to ten items per factor. It is important to mention that an effort was made to maintain a minimum number of items per factor to avoid making the instrument too long or difficult to be administered. Thus, four exclusion criteria were used to select the items, (a) the item affected or did not contribute to the internal consistency of the factor, (b) there was little interpretative consistency to maintain the item in the factor, (c) significant loads on other factors (difference lower than 0.50 between intra-factor loads), and (d) content redundancy between items in the same factor. Therefore, some items that had adequate factor load were excluded. With regard to the internal consistency of the factors found, it was verified that all factors had a correlation coefficient higher than 0.80 , and the dimension index of the total set of items was 0.87

After defining the dimension internal structure, its factors and total score were related and compared with the original dimension and the dimensions and facets of the other instruments. Table 3 shows the results of the correlations between the factors of the new dimension considering the original score.
The correlations between the total scores and the Criticism Avoidance dimension ranged between 0.23 and 0.45 . It was also observed a correlation of 0.70 between the total scores of the revised and original dimensions, indicating some similarity between them and demonstrating the changes introduced in the new set of items. In addition, the original dimension had the lowest correlations with the factors Anxious Preoccupation and Avoidance of Intimate Relations, while the highest correlation was found between the revised dimension and the Generalized Avoidance factor. Table 4 presents the results of the correlations between the factors, the total scores (original and revised) of the Criticism Avoidance dimension, and the Neuroticism and Extraversion facets of the NEO-PI-R.

It is important to note that the correlations between the factors of the revised dimension and the facets of the NEO-PI-R ranged from 0.08 to 0.56 , and those between the facets and the total score of the revised dimension ranged from 0.24 to 0.56 . Moreover, the correlations between the original total score of the dimension and the dimensions of NEO-PI-R ranged from 0.16 to 0.56 . In all factors, 
Table 3

Correlation between the factors of the revised and those of the original dimension

\begin{tabular}{lccccc}
\hline Dimension and Factor & 1 & 2 & 3 & 4 & 5 \\
\hline 1. Anxious Preoccupation & 1 & $0.45^{*}$ & $0.23^{*}$ & $0.73^{*}$ & $0.46^{*}$ \\
2. Generalized Avoidance & $0.45^{*}$ & 1 & $0.36^{*}$ & $0.87^{*}$ & $0.76^{*}$ \\
3. Avoidance of Intimal Relationships & $0.23^{*}$ & $0.36^{*}$ & 1 & $0.61^{*}$ & $0.24^{*}$ \\
4. Revised Avoidance & $0.73^{*}$ & $0.87^{*}$ & $0.61^{*}$ & 1 & $0.70^{*}$ \\
5. Original Avoidance & $0.46^{*}$ & $0.76^{*}$ & $0.24^{*}$ & $0.70^{*}$ & 1 \\
\hline
\end{tabular}

Note: *Significant at $p=0.01$.

Table 4

Correlations between the total score, factors and dimensions, and facets of Neuroticism (NEO-PI-R)

\begin{tabular}{|c|c|c|c|c|c|c|c|}
\hline \multirow[t]{2}{*}{ Dimension and Factor } & \multicolumn{7}{|c|}{ Neuroticism } \\
\hline & Ans. & Anger & Dep. & Emb. & Imp. & Vul. & Neu. \\
\hline Anxious Preoccupation & $0.40^{* *}$ & $0.26^{* *}$ & $0.34^{* *}$ & $0.44^{* *}$ & $0.33^{* *}$ & $0.49^{* *}$ & $0.53^{* *}$ \\
\hline Generalized Avoidance & $0.24^{* *}$ & $0.24^{* *}$ & $0.42^{* *}$ & $0.56^{* *}$ & $0.15^{*}$ & $0.46^{* *}$ & $0.49^{* *}$ \\
\hline Intimal relations Avoidance & $0.16^{*}$ & 0.04 & $0.17^{*}$ & $0.17^{*}$ & 0.08 & $0.23^{* *}$ & $0.20^{* *}$ \\
\hline Revised Avoidance & $0.35^{* *}$ & $0.26^{* *}$ & $0.44^{* *}$ & $0.56^{\star *}$ & $0.24^{* *}$ & $0.54^{* *}$ & $0.56^{* *}$ \\
\hline Original Avoidance & $0.24^{* *}$ & $0.23^{* *}$ & $0.37^{\star *}$ & $0.56^{* *}$ & $0.16^{*}$ & $0.47^{* *}$ & $0.48^{* *}$ \\
\hline \multirow[t]{2}{*}{ Dimension and Factor } & \multicolumn{7}{|c|}{ Extraversion } \\
\hline & Warm. & Gre. & Ass. & Act. & Sea. & PE. & Ext. \\
\hline Anxious Preoccupation & $-0.16^{*}$ & -0.08 & 0.01 & 0.05 & -0.02 & -0.04 & -0.07 \\
\hline Generalized Avoidance & $-0.27^{* *}$ & $-0.23^{* *}$ & -0.11 & $-0.24^{* *}$ & $-0.18^{* *}$ & $-0.23^{* *}$ & $-0.35^{* *}$ \\
\hline Avoidance of Intimal Relationships & $-0.16^{*}$ & $-0.14^{*}$ & 0.02 & -0.07 & -0.01 & -0.07 & -0.11 \\
\hline Avoidance Revised & $-0.28^{* *}$ & $-0.21^{\star *}$ & -0.05 & $-0.14^{*}$ & -0.11 & $-0.17^{*}$ & $-0.27^{* *}$ \\
\hline Original Avoidance & $-0.19^{* *}$ & $-0.14^{*}$ & -0.06 & $-0.20^{* *}$ & $-0.17^{*}$ & $-0.17^{*}$ & $-0.26^{* *}$ \\
\hline
\end{tabular}

Note: "Significant at $p=0.05 ;{ }^{* *}$ Significant at $p=0.01$.

Ans.: Anxiety; Dep.: Depressiveness; Emb.: Consciousness/Embarrassment; Imp.: Impulsiveness; Vul.: Vulnerability; Neu.: Neuroticism; Warm.: Warmth; Gre.: Gregariousness; Ass.: Assertiveness; Act.: Activity; Sea.: Search for Sensations; PE.: Positive Emotions; Ext.: Extraversion; NEO-PI-R: NEO Personality InventoryRevised.

the revised dimension had higher correlation than that of the original dimension, except for the Consciousness/Embarrassment facet, which had similar correlations to those of the original dimension. The correlations between the Criticism Avoidance revised dimension and Neuroticism, Vulnerability, and Consciousness/Embarrassment were higher than those of the original dimension. Comparing the factors of the revised dimension with those of the original dimension, it was found that Anxious Preoccupation had higher correlation with Neuroticism; Generalized Avoidance had higher correlation with the embarrassment facet; and Avoidance of Intimate Relations had higher correlation with Vulnerability although it had low correlations with all facets. Despite the differences between the total scores (original and revised) and the facets of Neuroticism, the difference found in the correlation of this factor with the total scores was not significant $(p>0.05)$.

Table 4 also shows information regarding Extraversion and its facets; the original and revised total scores had negative correlations with all facets of the Extraversion factor of the NEO-PI-R. The correlation of the revised dimension with Extraversion was higher when compared with that of the original dimension in the facets Warmth, Gregariousness, Positive emotions, and in the Extraversion dimension; although it was similar in this last facet. It was also observed that most 
Table 5

Correlation between Criticism Avoidance and PID-5 facets

\begin{tabular}{|c|c|c|c|c|}
\hline Dimension and Factor & Ans. & Dep. & Int. Av. & Av. \\
\hline Anxious preoccupation & $0.69^{* *}$ & $0.41^{* *}$ & $0.17^{*}$ & $0.28^{* *}$ \\
\hline Generalized Avoidance & $0.56^{* *}$ & $0.66^{* *}$ & $0.31^{* *}$ & $0.69^{* *}$ \\
\hline Intimal Relations Avoidance & $0.31^{* *}$ & $0.43^{* *}$ & $0.61^{* *}$ & $0.45^{* *}$ \\
\hline Total Avoidance Revised & $0.70^{* *}$ & $0.69^{* *}$ & $0.44^{* *}$ & $0.65^{* *}$ \\
\hline Original Avoidance & $0.47^{* *}$ & $0.50^{* *}$ & $0.18^{* *}$ & $0.53^{* *}$ \\
\hline
\end{tabular}

Note: " Significant at $p=0.05 ;{ }^{* *}$ Significant at $p=0.01$.

Ans.: Anxiety; Dep.: Depressiveness; Int. Av.: Intimacy Avoidance; Av.: Avoidance; PID-5: Personality Inventory for DSM-5.

correlations of the Criticism Avoidance factors with Extraversion were negative, and they were significantly lower than those with Neuroticism and higher than those with the Generalized Avoidance. Some factors such as Anxious Preoccupation and Avoidance of Intimate Relations had correlations close to zero with the facets of the NEO-PI-R; however, the latter had a more significant correlation with Warmth and Gregariousness. Similar to what was observed with Neuroticism, despite the differences between the total scores (original and revised) and the facets of Extraversion, the difference in correlation between the total scores was not significant. Table 5 presents the correlations between Criticism Avoidance and six facets of PID-5.

Table 5 shows that the correlations of the total score of the revised scale were clearly higher than those of the original scale for all facets of the PID-5. Both the original and revised dimensions had higher correlations with the facets Anxiety, Depressiveness, and Avoidance. As for the factors of the new dimension, Anxious Preoccupation showed higher correlation with Anxiety; Generalized Avoidance with Depressiveness and Avoidance; and Avoidance of Intimate Relations with Intimacy Avoidance. Furthermore, it was observed that the correlations of the IDCP with the PID-5 were significantly higher than those with the dimensions and facets of the NEO-PI-R in all cases, showing a significant difference $(p<0.01)$.

\section{Discussion}

The Criticism Avoidance dimension of the IDCP originally includes the assessment of personal characteristics, such as beliefs of incapacity and inadequacy, fear of humiliation, criticism and rejection, anxiety, and social and intimacy avoidance, and the desire for interpersonal relationships (Carvalho \& Primi, 2015). According to the study carried out by Abela (2013), this dimension is the most relevant for the avoidant personality disorder, as also evidenced by Carvalho (2011). As a result of the first stage of this study, 470 items were developed, of which, after refinement, 39 were selected for use in the constructs, including anxiety, feelings of inadequacy, and avoidance of intimacy (which were not included in the original version), and the constructs such as Social Avoidance and Isolation, which were included in the original items, were reinforced.

After psychometric analysis, the Criticism Avoidance revised dimension had a total of 18 items, including two original items and 16 new items. These items were divided into three factors: Anxious Preoccupation (4 items), Generalized Avoidance (10 items), and Avoidance of Intimate Relations (4 items), which had adequate internal consistency coefficients (Embretson, 1996; Nunnally, 1978).

In the first factor, Anxious Preoccupation, the items related to the concern about the future and the possibility of occurrence of unpleasant events and were grouped together. For example, the item "I'm always worried about the bad things that can happen". The following factor, Generalized Avoidance, contains a greater number of items since it refers to characteristics more commonly present in the underlying functioning of the dimension, such as a feeling of embarrassment when speaking in public and being in social situations, difficulty 
establishing interpersonal relationships, and fear of being the focus of attention. For example, the item "I only talk to people I do not know if there is no other way". Finally, the factor Avoidance of Intimate Relations, which has items focused on the difficulty getting emotionally involved and little interest in intimate friendships, were exemplified in the item "I prefer to avoid romantic relationships". The factors found had good psychometric indices, are in agreement with those in the reviewed literature (Clark, 1990; Krueger et al., 2011; Shedler \& Westen, 2004), and indicate the adequacy of the avoidant functioning assessment using the IDCP.

It was observed that most of the correlations among the factors of this dimension ranged from low to moderate, which suggests the possibility of discriminating individuals according to personality profiles using the Criticism Avoidance dimension. This should be verified in further studies and may be of great interest for the use of IDCP in the clinical context. With regard to the correlations between the factors with the original dimension, the lowest correlations were found with the factors Anxious Preoccupation and Avoidance of Intimate Relations, indicating that the revised dimension has these characteristics, which were poorly represented in the original dimension. Furthermore, the correlation between the total scores of the original and the revised versions suggests that the set of items developed are related with each other, but they are still different from the traits analyzed.

As for the correlations between the IDCP and the other instruments, considering the fact that the NEO-PI-R does not have any dimension directly related to the avoidant functioning, the researchers chose to investigate the correlations with factors that would theoretically be significant. Therefore, the dimension Neuroticism was selected due to its close relationship with unhealthy functioning, and Extraversion was selected due to its relationship with the need to be around other people (Costa Junior \& McCrae, 2009). The correlation between the Neuroticism factor and the revised dimension was higher than that with the original dimension, which suggests that the scale tends towards the assessment of higher level of personality pathology, as expected, indicating the adequacy of this IDCP dimension since the instrument was developed primarily to evaluate pathological functioning of personality (Carvalho \& Primi, 2015). The facets of Neuroticism with the highest correlation with the total score of the revised dimension were Vulnerability and Embarrassment, which is expected, since these facets are related to characteristics such as nervousness and inability to cope with stress and can demonstrate the avoidant functioning characterized by difficulty in establishing relations and feeling bad in social situations considered unpleasant. The Vulnerability facet had higher correlation with the Anxious Preoccupation factor, but, despite the consistency, it was expected that this factor would correlate more with the facets Anxiety and Embarrassment since they are characteristics that are present in this category of the revised dimension. Finally, the factor Avoidance of Intimate Relations had lower correlation with the facets of Neuroticism, suggesting that this dimension of NEO-PI-R does not have items that assess the functioning of this factor of Criticism Avoidance.

The correlations of the Extraversion dimension of the NEO-PI-R with the IDCP were mostly negative and significantly lower than those with Neuroticism. On the one hand, negative correlations were expected as the avoidant functioning is directly related to the difficulty to be around people, and the high scores of extraversion suggest a tendency to be among people (Costa Junior \& McCrae, 2009). On the other hand, fairly low correlations were not expected, considering a continuum between a more pathological personality functioning (in this case represented by the Criticism Avoidance dimension) and a healthier functioning (represented by the Extraversion dimension). In order to verify whether the absence of a continuum between the IDCP dimension and the NEO-PI-R factor could be explained by problems in the representativeness of the dimension construct, the Extraversion dimension and its facets were also correlated with the PID-5 facets. However, the correlations found were also low, and none of them was higher than 0.30. Future studies should investigate this issue more deeply. It should also be considered that the NEO-PI-R was developed to assess personality traits within normal range 
measurements (Costa Junior \& McCrae, 2009), unlike the IDCP (Carvalho \& Primi, 2015), which was developed to assess pathological personality traits. The most modest moderate correlations between the instruments were possibly affected by these attributes, which were also indicated by the lack of significance in the differences between the correlations with the total scores (original and revised), corroborating the ranges covered in these instruments.

Additionally, it was verified that the correlations of the IDCP with the PID- 5 were more significant than those found for the NEO-PI-R, and the correlations of the revised version with the PID-5 were higher than those with the original dimension, suggesting that both the PID- 5 and the IDCP assess higher level of personality pathology, which was expected, and it also provides evidence for the validity of the IDCP dimension. It is also worth mentioning that the significant difference between the correlations of the revised total score and the original total score with the facets of the NEO-PI-R also indicate a great similarity between the dimension and original versions. The correlations found were considered typical and expected since the Anxious Preoccupation factor of the IDCP had the highest correlation with Anxiety (excessive concerns especially about bad things that the subject believes that will occur in the future) of the PID-5; Generalized Avoidance had higher correlation with Avoidance (avoidance of social activities, not showing interest in relating and preference for being alone) and Depressiveness (belief that life is bad and there is nothing you can do to improve and suicidal thoughts), and Avoidance of Intimate Relations had higher correlation with Intimacy Avoidance (avoidance to establish intimate relationships and/or romantic and/or sexual, lack of attachment to interpersonal relationships).

\section{Final Considerations}

The main purpose of this study, to revise the Criticism Avoidance dimension of the IDCP and its adequate psychometric properties, was achieved according to the results. Validity evidence was its relationship with other variables, and the revised dimension had high reliability coefficients. It is important to highlight that the tendency of the IDCP items to assess higher level of personality pathology seems to have been improved, resulting in a revised dimension suitable for the determine profiles typical of the avoidant personality disorder. However, further studies are needed to identify these profiles and to administer the revised dimension in people diagnosed with personality disorder.

As for the internal structure of the scale, it can be said that the three-factor model found is consistent with the literature on avoidant functioning, not in terms of the number of factors found but in terms of the theoretical close relationship of the items that represent each factor. It was found an enhanced representativeness of the constructs in the revised dimension that was not a characteristic of the original dimension. The results obtained were favorable for the revised dimension since the correlations with the instruments were, in general, expected, especially with regard to the correlations between the revised dimension and the PID-5.

Finally, the limitations of this study are related to the number and characteristics of the participants. A small sample was analyzed and it did not include patients with personality disorder. Furthermore, the internal consistency or Cronbach's alpha, which was sometimes less than 0.70 (acceptable cutoff value), must be considered in the correlations tests. It is suggested that future studies are carried out to replicate the structure found in the different samples, focusing on the relevance of clinical samples.

\section{Contributors}

All authors made substantial contributions to the research design and conception, data analyses, and manuscript writing.

\section{References}

Abela, R. K. (2013). Evidências de validade para o Inventário Dimensional Clínico da Personalidade (IDCP) com base nos perfis de participantes com diagnóstico 
psiquiátrico (Tese de Doutorado não-publicada). Universidade Federal de São Paulo.

American Psychiatry Association. (2003). Diagnostic and Statistical Manual of Mental Disorders (4th ed.). Washington: Author.

American Psychiatry Association. (2013). Diagnostic and Statistical Manual of Mental Disorders (5th ed.). Washington: Author.

Carvalho, L. F., Bartholomeu, D., \& Silva, M. C. R. (2010). Instrumentos para avaliação dos transtornos da personalidade no Brasil. Avaliação Psicológica, 9(2), 289-298.

Carvalho, L. F. (2011). Desenvolvimento e verificação das propriedades psicométricas do Inventário Dimensional Clínico da Personalidade (Tese de doutorado não-publicada). Universidade São Francisco, Itatiba.

Carvalho, L. F., Sette, C. P., Capitão, C. G., \& Primi, R. (2014a). Propriedades psicométricas da versão revisada da dimensão necessidade de atenção do inventário dimensional clínico da personalidade. Temas em Psicologia, 22(1), 147-160. https://doi.org/10.9788/ TP2014.1-12

Carvalho, L. F., Souza, B. D. B., \& Primi, R. (2014b). Psychometric properties of the revised conscientiousness dimension of Inventário Dimensional Clínico da Personalidade (IDCP). Revista de Psiquiatria do Rio Grande do Sul, 36(1), 23-31. https://doi.org/10.1590/2237-6089-20 13-0024

Carvalho, L. F., \& Primi, R. (2015). Development and internal structure investigation of the Dimensional Clinical Personality Inventory (IDCP). Psicologia: Reflexão e Crítica, 28(2), 322-330.

Carvalho, L. F., Primi, R., \& Stone, G. E. (2014). Psychometric properties of the Inventário Dimensional Clínico da Personalidade (IDCP) using the Rating Scale Model. Avances en Psicología Latinoamericana, 32(3), 433-446.

Clark, L. A. (1990). Toward a consensual set of symptom clusters for assessment of personality disorder. In J. N. Butcher \& C. D. Spielberger (Orgs.), Advances in personality assessment. New Jersey: Lawrence Erlbaum Associates.

Costa Junior, P. T., \& McCrae, R. (2009). NEO-PI-R - Inventário de Personalidade NEO Revisado - Manual. São Paulo: Vetor.

Embretson, S. E. (1996). The new rules of measurement. Psychological Assessment, 8(4), 341-349. https://doi. org/10.1037/1040-3590.8.4.341

Hayton, J. C., Allen, D. G., \& Scarpello, V. (2004). Factor retention decisions in exploratory factor analysis: A tutorial on parallel analysis. Organizational Research Methods, 7(2), 191-205. https://doi.org/10.1177/ 1094428104263675

Hutz, C. S. (2009). Ética na avaliação psicológica. In C. S. Hutz (Org.), Avanços e polêmicas em avaliação psicológica (pp.297-310). São Paulo: Casa do Psicólogo.
Hutz, C. S., \& Bandeira, D. R. (2003). Avaliação psicológica no Brasil: situação atual e desafios para o futuro. In O. H. Yamamoto \& V. V. Gouveia (Orgs.), Construindo a psicologia brasileira: desafios da ciência e prática psicológica (pp.61-277). São Paulo: Casa do Psicólogo.

Krueger R. F., Derringer J., Markon, K. E., Watson D., \& Skodol, A. E. (2011). Initial construction of a maladaptive personality trait model and inventory for DSM-5. Psychological Medicine, 42(9), 1-12. https:// doi.org/10.1017/S0033291711002674

Millon, T., \& Davis, R. D. (1996). Disorders of personality DSM-IV and beyond. Mahwah: Wiley.

Millon, T., Millon, C. M., Meagher, S., Grossman, S., \& Ramanath, R. (2004). Personality disorders in modern life. New Jersey: Wiley.

Millon, T., \& Grossman, S. (2007a). Moderating severe personality disorders. New Jersey: John Wiley \& Sons.

Millon, T., \& Grossman, S. (2007b). Overcoming resistant personality disorders. New Jersey: John Wiley \& Sons.

Millon, T., Grossman, S., \& Tringone, R. (2010). The millon personality spectrometer: A tool for personality spectrum analyses, diagnoses, and treatments. In T. Millon, R. F. Krueger, \& E. Simonsen (Orgs.), Contemporary directions in psychopathology: Scientific foundations of the DSM-V and ICD-11 (pp.391-418). New York: The Guilford Press.

Nunnally, J. C. (1978). Psychometric theory. New York: McGraw-Hill.

Shedler, J., \& Westen, D. (2004). Dimensions of personality pathology: An alternative to the five factor model. American Journal of Psychiatry, 161(10), 1743-1754. https://doi.org/10.1176/appi.ajp.161.10.1743

Skodol, A. E., Clark, L. A., Bender, D. S., Krueger, R. F., Morey, L. C., Verheul, R., ... Oldham, J. M. (2011). Proposed changes in personality and personality disorder assessment and diagnosis for DSM-5 Part I: Description and rational. Personality Disorders: Theory, Research, and Treatment, 2(1), 4-22. https://doi.org/ 10.1037/a0021891

Yazigi, L., Semer, N. L., Botelho, N. P., Barros, R., Diaz, L. S., \& Fiore, M. L. M. (2013). Os desafios da avaliação psicológica nos transtornos da personalidade. In L. F. Carvalho \& R. Primi (Orgs.), Perspectivas em psicologia dos transtornos da personalidade (pp.168-195). São Paulo: Casa do Psicólogo.

Zuccolo, P. F., Corhs, F., \& Savoia, M. G. (2013). Psicopatologias e o conceito da personalidade. In L. F. Carvalho \& R. Primi (Orgs.), Perspectivas em psicologia dos transtornos da personalidade (pp.8-23). São Paulo: Casa do Psicólogo.

Watkins, M. W. (2006). Determining parallel analysis criteria. Journal of Modern Applied Statistical Methods, 5(2), 344-346.

Received: July 29, 2014

Final version: May 14, 2015

Approved: May 25, 2015 
